\title{
- KOMPARATIVNA ANALIZA ODNOSA IZMEĐU OČEVA I SINOVA U DRAMAMA OLUJA CAO JUA I GOSPODA GLEMBAJEVI MIROSLAVA KRLEŽE ${ }^{1}$
}

\author{
TEODORA TODORIĆ MILIĆEVIĆ 2 \\ Univerzitet u Beogradu, \\ Filološki fakultet \\ Beograd, Srbija
}

Ovaj rad se bavi komparativnom analizom odnosa između očeva i sinova u dramama Oluja Cao Jua i Gospoda Glembajevi Miroslava Krleže. Obe drame su nastale pod snažnim uticajem skandinavske dramske tradicije, prvenstveno Ibzena. U njima se pronalaze mnoge sličnosti kako u dramskoj tehnici tako i u upotrebi gotovo istih simbola i motiva, na šta ćemo se osvrnuti u prvom delu rada. U drugom delu rada ćemo analizirati odnos između očeva i sinova, te pokazati kako je patrijarhat, stvarajući autoritarne očinske figure i podređene sinove, oblikovao sukob između likova u ovim dramama.

Ključne reči: kineska književnost, hrvatska književnost, drama, komparatistika, Oluja, Gospoda Glembajevi.

U vremenskom rasponu od samo pet godina objavljene su dve drame koje po stilu i izboru tema izuzetno podsećaju jedna na drugu, a čiji autori ne samo što nisu bili u neposrednom kontaktu, već dolaze iz sasvim različitih kulturnih miljea. Reč je o Oluji (1934), drami kineskog pisca Cao Jua, i Krležinoj drami Gospoda Glembajevi (1929). S namerom da utvrdimo šta povezuje ove autore i kako su oni obradili neke od glavnih motiva u svojim delima, u ovom radu ćemo se baviti komparativnom analizom oluje i Gospode Glembajevi. Na prvom mestu, istaći ćemo paralele u izboru teme i upotrebi pojedinih motiva, kao i sličnosti u dramskoj tehnici, u kojoj su se Cao Ju i Krleža ugledali na Henrika Ibzena. Potom ćemo analizirati odnos između očeva i sinova u dramama, ali s naglaskom na junacima koji su najzastupljeniji u delima, kao što su Džou Pujuen i

1 Rad je nastao u okviru projekta Knjiženstvo, teorija i istorija ženske književnosti na srpskom jeziku do 1915. godine, br. 178029, koji finansira Ministarstvo prosvete, nauke i tehnološkog razvoja Republike Srbije.

2 Kontakt podaci (Email): teodora.todoric.milicevic@gmail.com 
Džou Ping u Oluji, i Ignjat i Leone Glembaj u Gospodi Glembajevima. Ispitujući razloge za sukob između tih likova, ukazaćemo na razorne posledice patrijarhata, koji je zajednički činilac kako kineskog tako i hrvatskog društva.

Cao Jueva Oluja u centru radnje ima propast tradicionalne konfucijanske porodice Džou. Samovoljni i okrutni vlasnik rudnika Džou Pujuen u mladosti započinje ljubavnu vezu s devojkom iz nižeg staleža Šiping, koju, pod pritiskom društvenih stega, ali i zbog sopstvenog kukavičluka, tera iz kuće s novorođenčetom, dok zadržava starijeg sina Džou Pinga. Godinama kasnije, Pujuen je u braku s Fanji, s kojom ima sina Džou Čunga, te živi u uverenju da su Šiping i njegovo drugo dete mrtvi. S druge strane, Ping je melanholičan mladić koji je u tajnoj vezi sa sluškinjom Sifeng, dok istovremeno pokušava da zaboravi na ljubavnu aferu koju je imao tri godine ranije s maćehom. Kako drama odmiče i događaji se razvijaju, otkrivamo da je Šiping udata za slugu Džouovih i da je zapravo živa, kao i njen i Pujuenov sin, Lu Dahai, koji, ironijom sudbine, radi u Pujuenovom rudniku i vođa je radničkog štrajka. Saznajemo i da je Sifeng Pingova polusestra, što na koncu dovodi do tragičnog ishoda.

U Gospodi Glembajevima zaplet je jednostavniji. Protagonista drame, Leone Glembaj, vraća se u porodičnu kuću na proslavu jubileja svoga oca, bogatog i moćnog bankara Ignjata Glembaja. Od samog početka vidimo da je Leone stranac u roditeljskoj kući i data nam je duboka psihologizacija njegovog lika preko dijaloga koje vodi sa snajom Anđelikom i ostalim ukućanima i gostima. Iz razgovora sa Zilberbrantom, koji načuje Ignjat, a u kojem Leone optužuje maćehu, barunicu Kasteli, da vara muža, razvija se verbalni konflikt između oca i sina. Na prvi pogled, sukob nastaje zbog Leoneovih optužbi, ali se kroz razgovor otkrivaju dublji razlozi za netrpeljivost, kao i Leoneova veza s maćehom pre jedanaest godina. To saznanje dovodi do Ignjatove smrti, koji dobije infarkt usled prevelikog uzbuđenja, dok Leone kasnije u naletu besa ubija barunicu.

Ukratko smo se osvrnuli na radnje obe drame da bismo lakše pristupili glavnoj temi rada - poređenju odnosa između očeva i sinova. Ovaj osvrt nam takođe ističe sličnosti u izboru tema u dramama, što se prvenstveno odnosi na patrijarhalno izgrađen odnos između autoritarnog oca i podređenog sina, koji iz besa i revolta prema ocu otpočinje ljubavnu vezu s maćehom.

Oluja i Gospoda Glembajevi objavljeni su u doba nestabilnosti i previranja u društvima o kojima govore. U obe drame vidimo kako su istorijske okolnosti datih trenutaka uticale na formiranje ideološke pozadine u okviru koje se odigrava radnja. Oluja je nastala kad i promene u kineskom društvu usled formiranja Republike Kine, odbacivanja feudalizma i s prodorom ideja sa Zapada koje su kod Kineza podstakle preispitivanje tradicije, dok su Gospoda Glembajevi napisani posle Prvog svetskog rata i u njima, kako uočava Brajović, možemo naći analogiju između propasti građanske porodice s propašću evropskog društva (1997: 16-17). Premda obe drame govore 0 promeni i manama jednog sistema, kao i o lomljenju dotadašnje slike sveta, važno je imati na umu da taj svet nije isti. 
Upravo je društvo koje oblikuje živote protagonista i koje je meta kritike prva nit kojom bismo povezali ove dve drame s Ibzenom, velikim kritičarem norveškog društva i ocem moderne drame. Mada geografski i ideološki značajno razdvojeni, Cao Ju i Krleža nalaze zajedničku tačku u norveškom dramskom piscu koji je snažno uticao na njihovo stvaralaštvo, o čemu su i sami govorili. Tako je Cao Ju u mladim danima glumio u dramama režiranim po Ibzenovim tekstovima, dok je na fakultetu napisao o njemu diplomski rad (Pavlović 2015: 184-185). Cao Juevo interesovanje za norveškog autora ne čudi, s obzirom na Ibzenovu popularnost u Kini početkom 20 . veka. ${ }^{3} S$ druge strane, Krleža u Osječkom predavanju iz 1928. godine govori kako je počeo da piše psihološke dijaloge po uzoru na nordijsku školu, te da je „snaga dramske radnje [...] ibsenski konkretna, kvalitativna, a sastoji se od psihološke objektivacije pojedinih subjekata, koji na sceni doživljavaju sebe i svoju sudbinu" (Vidan 1968: 325). Kao što ćemo videti u nastavku rada, oba autora, nadahnuti Ibzenovom dramaturškom tehnikom i izborom tema, grade psihološki složene likove čija se sudbina dešava u neuralgičnim društvima u kojima žive.

Da bismo na konkretnom primeru videli neke od sličnosti između Ibzena, Cao Jua i Krleže, uzećemo za primer Ibzenovu dramu Aveti ${ }^{4}$ te je u kratkim crtama uporediti s Olujom i Gospoda Glembajevima. Baš kao i Aveti, Oluja i Gospoda Glembajevi grade se oko događaja koji su se desili u prošlosti, odnosno jedne velike tajne čije otkrivanje prouzrokuje tragičan ishod. Služeći se retrospektivnom ekspozicijom, odnosno preplitanjem prošlih i sadašnjih događaja, u dramama se postepeno otkriva prošlost koja tragično utiče na sadašnjost. Takođe, sve tri drame su analitičke, što znači zatvorenog tipa, tj. radnja započinje neposredno pred katastrofu.

Sva tri autora vešto koriste vremenske prilike kao simbole. Promena atmosfere iz mraka i kiše, koji su prisutni u celoj drami, u svitanje i lep sunčan dan na kraju Aveti simbolički označava razotkivanje tajne kojaje u srži drame (Pavlović 2015: 230-231). Na samom početku Oluje, u sobi je „zagušljivo i sparno, a vazduh težak” (Cao Ju 2003: 20), dok "napolju nema sunca, nebo je sivo, atmosfera pred pljusak" (Cao Ju 2003: 20), da bi u drugom činu vreme bilo „tmurno i sparnije” (Cao Ju 2003: 66), a u trećem i četvrtom konačno došlo do nevremena. Vremenske (ne)prilike usklađene su s razvojem radnje i podstiču napetost usled iščekivanja razrešenja. U Oluji je oluja toliko važan element da se, u skladu s piščevom namerom, može posmatrati kao zaseban lik u drami (Pavlović 2015: 218), ali i kao personifikacija lika Fanji, što je pokazala Pavlović (2015: 222-228). Naziv Cao Jueve drame ujedno je jedan od glavnih motiva u Gospodi Glembajevima, u kojima se na sličan način menja atmosfera. Oluja se utišava kako se otkrivaju tajne i kako eskalira sukob između Leonea i Ignjata, te se na kraju drame čuje "cvrkut ptica u vrtu" (Krleža 1997: 187), što je u kontrastu sa zvonima s početka drame koja „zvone više na pogreb, nego na jubilej" (Krleža 1997: 38). Kada se sve svršilo, sve tajne se otkrile i desila tragedija, priroda se utišala i život je nastavio svojim tokom.

Još jedna spona između ove tri drame jeste tema incesta. Za razliku od Aveti i Oluje, u Gospodi Glembajevima ne postoji pravi, rodoskrvni incest, već samo društveno neprihvatljiva veza između maćehe i pastorka. U Avetima, s druge strane, ova tema ne

30 recepciji Ibzena u Kini napisane su mnoge studije. Videti: He (2004), He (2007), Pavlović (2015).

4 Komparativnom analizom Aveti i Oluje na srpskom jeziku bavile su se Pavlović (2015) i Maksimović (2018). 
postoji, već samo pravi incest između polubrata i polusestre, dok su u Oluji obrađene obe vrste odnosa. Ljubavna veza između maćehe i pastorka, prisutna u Oluji i Gospodi Glembajevima, postoji još od antičke drame i nalazimo je u Euripidovom Hipolitu, te je zatim obrađena u više dela, od kojih je najpoznatija Rasinova Fedra. Za razliku od Euripidove drame, gde pastorak odbija svoju zavodljivu maćehu, u Oluji i Gospodi Glembajevima pastorci se svesno upuštaju u ljubavni odnos. ${ }^{5}$ Iako Ping i Leone nemaju sasvim isti odnos s maćehama, obojica ulaze u ljubavne veze iz revolta prema ocu, 0 čemu ćemo detaljnije govoriti u nastavku rada.

\section{2}

Analizu sukoba između očeva i sinova počećemo od Oluje, u kojoj nikada ne dođe do direktnog i oštrog sučeljavanja Pujuena i njegovih priznatih sinova - Pinga i Čunga. Pujuenu najveći otpor pruža Dahai, ali ne kao sin, već kao vođa radničkog štrajka. Iako je atmosfera u Oluji sve vreme napeta, što dočarava zagušljivost prostorija koja je u kontrastu s provalom oluje koja usledi kad se približimo raspletu, i uprkos brojnim konfliktnim situacijama u kojima se nalaze likovi, Pujuenov i Pingov sukob ostaje u sferi prećutanog, a Čungov blagi revolt se brzo ugasi. $S$ druge strane, nije sasvim jasno ni ko je glavni lik u drami. Ukoliko se delo čita iz perspektive klasnog sukoba, glavni lik je Pujuen, jer je oličenje feudaliste koji sve ukućane podređuje svojoj volji i okrutno postupa s radnicima svog rudnika, dok bi po drugim čitanjima to mogla biti Fanji (He 2004: 182). Nasuprot Oluji, u Gospodi Glembajevima sukob između oca i sina, Ignjata i Leonea, dominira u drami, anticipiran je od samog početka i dostiže vrhunac u Ignjatovoj smrti. Leone je nesumnjivo protagonista Gospode Glembajevih, drama evolvira oko njegovog unutrašnjeg nemira i duševnog rastrojstva ili, kako za njega kažu Fabrici, Šarlota i Ignjat - Leone je überspannt, prenapet (Krleža 1997: 52, 82, 110). Ta prenapetost je odlika kako Leoneova tako i cele drame.

Spomenuli smo da neka čitanja navode Pujuena kao glavnog lika Oluje i da su ona uglavnom fokusirana na klasni sukob (He 2004: 182). Međutim, iako postoji kritika feudalnog društva i motiv radničkog štrajka zbog nepovoljnih uslova u rudniku, drama nije izraženo politička kao mnoge napisane u tom periodu u Kini, već bismo je pre svrstali u porodičnu. Pujuen jeste bogati konzervativni tradicionalista, ali je motiv klasne borbe tek usput spomenut, mada je u kasnijim, prerađenim, izdanjima drame proširen (Pavlović 2014: 193). Naime, sam Cao Ju je rekao da je Oluja jedna narativna poema, a ne društvena drama, mada je kasnije ipak prihvatio i njena politička tumačenja (Lv 2007: 182). Ako govorimo o ideološkoj poziciji, socijalizam i borbu za prava radnika predstavlja vođa radničkog protesta - Lu Dahai, ali je za dramsku radnju značajnije to što je Pujuenov sin (mada to ne sazna do samog završetka drame) jer stoji u suprotnosti i konfliktu s ocem, odnosno tiraninom. Kada je reč o Gospodi Glembajevima, Kralj u Uvodu u dramaturgiju kaže da u društveno-kritičkoj drami autor govori kroz usta junaka i daje svoju vrednosnu

5 Vredi napomenuti da je, osim antičke drame, na stvaralaštvo Cao Jua izuzetno uticao Judžin o'Nil, a u ovom konkretnom slučaju 0'Nilova drama Čežnja pod brestovima, u kojoj pastorak i maćeha takođe otpočinju ljubavnu vezu. Više o tome videti u Lau (1970). 
perspektivu, za šta primer nalazi upravo u Leoneu kroz kojeg govori Krleža (1966: 33). Ako uzmemo u obzir društveni kontekst u kojem je napisana drama, Krležine političke stavove, a, naravno, i sam tekst, lako je uočiti daje u klasnom sukobu, koji je izuzetno važan u drami, vrednosna perspektiva Gospode Glembajevih okrenuta protiv aristokratije, gde je Ignjat oličenje stare buržoazije, društva koje doživljava svoj pad posle Prvog svetskog rata. Leone prezire licemerje i okrutnost kako Ignjatovo tako i ostalih članova porodice, koji mare samo za novac, položaj u društvu i ugled. Kao što vidimo, premda u obe drame postoji sukob stare i nove generacije, vladajuće, bogate klase i nižeg društvenog sloja, Gospoda Glembajevi su politički značajno obojeniji od Oluje.

Međutim, iako u Glembajevima postoji eksplicitnija kritika društva, odnos između očeva i sinova ne možemo razumeti ako ne analiziramo ulogu iznačaj patrijarhata.U obe drame dva dominantna oca podređuju sinove svojoj volji i pritiskaju ih očekivanjima. Taj pritisak je povećan jer su Pujuen i Ignjat uspešni bogataši koji imaju značajan ugled u društvu, te otuda mare za mišljenje okoline i očuvanje svog bogatstva. Nasuprot njima stoje sinovi koji na različite načine pokušavaju da formiraju svoj identitet $i$ oslobode se očevih stega. U Oluji, Pujuenova autoritarnost se ispoljava u odnosu sa svima koji su mu podređeni, te je Dahai, igrom sudbine, takođe pod represijom oca, baš kao i Ping i Čung. Kada, međutim, dođe do štrajka, a potom i sukoba između Pujuena i Dahaija, Ping se solidariše s ocem i fizički se obračunava s Dahaijem, dok Čung od samog početka ima empatiju prema radničkom štrajku i Dahaiju. To su ujedno i tri načina na koje se sinovi u Oluji nose s Pujuenovom represijom - Dahai otvoreno stupa u konflikt, Ping internalizuje očev autoritet, dok Čung diplomatski pokušava da reši nesuglasice i nada se da će otac imati razumevanja za njegova i tuđa osećanja. Nasuprot tome, u Gospodi Glembajevima vidimo jasne primere "dobrih" sinova i "lošeg" sina, odnosno onih koji se pokoravaju volji oca i ispunjavaju njegova očekivanja (Puba i pokojni Ivan, koji je bio očeva glavna uzdanica i ponos) i sina koji se suprotstavlja ocu (Leone).

Od sva tri odnosa između oca i sina, u Oluji se najviše pažnje posvećuje Pujuenu i Pingu, te ćemo se njima najviše baviti. Premda, kako drama odmiče, Ping sve više pokazuje osobine svog oca, u prošlosti se opirao očevom autoritetu, i to tako što je bio u vezi s maćehom Fanji. Ipak, njegov bunt je tih $i$ kukavički, čega je Ping svestan, jer sam kaže da se oseća "kao miš koji je ugrizao lava dok spava”" (Cao Ju 2003: 52). Iza takvog ponašanja zapravo se krije Pingova želja da bude upravo kao svoj otac, slobodan da radi šta želi i kako želi, ali ga strah od očevog autoriteta, kao i od sopstvene nemoći i slabosti, parališe da se ostvari kao ličnost. U Pingu se sve vreme bore strahopoštovanje i potisnuta mržnja prema ocu. Kada mu Fanji kaže da je Pujuen licemer koji je zapravo oterao Pingovu majku jer je bila siromašna, Ping se ne obazire na te optužbe (Cao Ju 2003: 73). U didaskaliji koja se odnosi na Pingovu pojavu, stoji da se on zapravo divi ocu zbog tvrdoglavosti i bezosećajnosti jer su upravo to osobine koje Ping nema (Cao Ju 2003: 52). Ove osobine, iako negativne, upravo su one koje odlikuju uspešnog muškarca na vrhu patrijarhalne lestvice. Ping je svestan da je kukavica, da ne liči na svoga oca i da nije u stanju da ispuni očeva očekivanja. On se povremeno tiho suprotstavlja očevom autoritetu tako što pije, kocka se, čak ponekad ide u katoličku crkvu (Cao Ju 2003: 50), ali istovremeno krije svoje navike.

Kao što smo rekli, Leone je „loš sin" u porodici, koji u više navrata naglašava da nije sin svoga oca, da nije, kao što je bio njegov pokojni brat Ivan, „punokrvni Glembaj” 
(Krleža 1997: 119) ili poput Pube koji hladnokrvno i racionalno pronalazi rešenja za svaki zločin Glembajeva. Leone se sve vreme opire svojoj „glembajevštini”, želi pobeći od nje. Gledajući portrete starih Glembaja, Leone kaže: „,[...] ja nisam nikakav jubilarac ni bankar! Ja sam u ovoj kući prolaznik, meni ove slike govore stvari mnogo tamnije od jedne zdravice! Za vas onaj Glembaj drži u ruci crkvu, a za mene krvav nož!" (Krleža 1997: 60) Za razliku od svoje braće, koji su (bili) po očevoj volji, Leone voli slikarstvo, umetnost, sve ono što ne odlikuje muškarca kakav je njegov otac, odnosno muškarca koji je glava porodice. Ovde u jasnom kontrastu stoje umetnost i bankarstvo, simboli duhovnog i materijalnog sveta. Kao što Leone prezire Ignjatov novac, tako Ignjat na Leoneove slike gleda kao na "bezvrijedan materijal: uljenim bojama zamazano platno" (Krleža 1997: 109). Leoneova nesreća leži u tome što je svestan svoje porodice, što zna šta znači biti Glembaj, ali i zato što ne može pobeći od toga. Uprkos opiranju i poricanju svoje prirode, Leone na kraju izazove očevu smrt i ubije barunicu u naletu besa, te dramu završava s krvavim makazama u ruci.

Nasuprot Pingu, koji sve vreme pokušava da bude kao otac, u Oluji stoje druga dva sina - Čung i Dahai. Premda i dalje jako mlad i osećajan, Čung nalazi mnogo hrabrosti da se, makar oprezno i diplomatski, suprotstavi Pujuenu. On je sve suprotno od surovog pater familijasa - emotivan je, saosećajan, želi da pomogne Sifeng da završi školu, mari za radnički štrajk. Kada razgovaraju o problemima u rudniku, Čung se otvoreno zalaže za prava radnika i ne prestaje da brani svoje stavove, iako to čak razljuti Pujuena (Cao Ju 2003: 57). Nažalost, na Čungovom primeru vidimo kako Pujuenova okrutnost ruši iluzije mladog čoveka. Tako Čung, dok razgovara s Fanji o tome kako je zaljubljen u Sifeng, veruje da će otac ipak naći razumevanja za njegove emocije (Cao Ju 2003: 50), ali nakon scene $u$ kojoj Pujuen primora Fanji da popije lek, Čung odustaje od razgovora o Sifeng i poraženo konstatuje da je "majka izgleda bila u pravu" (Cao Ju 2003: 60) kada ga je upozorila da će mu „otac jednom rečju uništiti sve snove”" (Cao Ju 2003: 50). Svestan da je pokorio i Čunga, Pujuen mu kaže da ode iz prostorije, da bi ga posle dva koraka pozvao da se vrati da mu kaže još koju reč. Čung nakon toga automatski zastaje posle dva koraka da pita oca da li je potrebno još nešto i traži dozvolu da ode (Cao Ju 2003: 61). Iako kratka, ova scena nam pokazuje koliko je snažan Pujuenov autoritet is koliko uspeha manipuliše sinovima. Odnos između Pujuena i Čunga značajan nam je i da bismo razumeli Pinga, jer je i on verovatno nekada bio poput svog mlađeg brata, ali ga je otac na kraju slomio.

S druge strane, Dahai je smeo i slobodan da se suprotstavi autoritetu, u ovom slučaju vlasniku rudnika u kojem radi, ali u isto vreme, ne znajući, i svome ocu. Dahai je povremeno prek i autoritaran, jer naređuje svojoj sestri i stalno se sukobljava s očuhom. Svojim ponašanjem Dahai se u nekim aspektima nesvesno potvrđuje kao "sin svoga oca", slobodan, sposoban i samovoljan, premda ideološki potpuno drugačije opredeljen, za razliku od Pinga koji želi biti dobar sin i nalik ocu, ali u tome ne uspeva, ili za razliku od Čunga koji je nežniji i blaži. Paradoksalno, Ping liči na oca u pogledu kukavičluka i nespremnosti da se izbori za vezu sa Sifeng, jer kao što je Pujuen svojevremeno zbog društvenih normi odlučio da odbaci Šiping, devojku iz nižeg društvenog staleža, tako i Ping planira da ode od Sifeng i ne usuđuje se da obelodani njihov odnos.

Osim što je u napetoj vezi sa Sifeng, Ping ima i nerešen odnos s Fanji. Ping i Leone nalaze zajednički način da se "svete" očevima i uruše njihov autoritet, a to je stupanje u 
vezu s maćehama. ${ }^{6} \mathrm{U}$ trenutku kada se odvijaju radnje drama, oba junaka su prekinula veze $s$ Fanji, odnosno Šarlotom. Veze u kojima su bili nisu iste prirode. Ping i Fanji su imali romansu zasnovanu na ljubavi, zbog čega je Pingu teško da zaboravi na taj događaj. Dok je bio u ljubavnoj vezi s Fanji, iako se kasnije sve vreme kajao zbog toga jer se osećao kao da je izdao oca, Ping je ipak postupio onako kako želi i oseća. Jer, kako Pavlović primećuje , odnos s maćehom ujedno je i simbol Pingove pobede nad očevim autoritetom" (2014: 241). Ping i Fanji nalaze se u sličnoj situaciji, oboje trpe Pujuenovu represiju i pate zbog nedostatka očeve, odnosno suprugove ljubavi. Njihov raskid teško pada Fanji baš zato što je Ping bio jedini tračak svetlosti u njenom životu i probudio je stvari za koje je mislila da su nestale, kako kaže: „ja sam već bila pripremila kovčeg i čekala da umrem, ali me je jedan čovek, ipak, vratio u život, pa onda zanemario, ostavio me da venem, da polako umrem od žeđi" (Cao Ju 2003: 74). Ona je daleko hrabrija i spremnija da se suprotstavi Pujuenu, dok se Ping, iako ga i dalje muče emocije koje gaji prema Fanji, ne odlučuje da ostane u vezi s njom i, u krajnjem ishodu, otvoreno se suprotstavi ocu.

Kod Leonea Glembaja pak imamo drugačiju situaciju. Leone i Šarlota su davno bili zajedno, dok je on još bio student. Za razliku od Fanji, koja je privlačna izavodljiva, Šarlota je osim toga i manipulativna. Ona svesno zavodi da bi ispunila svoje namere, tako da kod nje i Leonea teško da možemo govoriti o iskrenoj ljubavi. Uprkos različitim prirodama odnosa, stupajući u vezu sa svojim maćehama, Ping i Leone uspevaju da stanu na mesto svojih očeva i da se podsvesno, makar trenutno, izbore s njihovim autoritetom. Dok je bio u vezi s Fanji, Ping je u naletu strasti rekao da mrzi oca i da mu želi smrt (Cao Ju 2003: 74), a Leone je izazvao očevu smrt upravo priznanjem nekadašnje veze sa Šarlotom.

Svest o tome ko su i kakvi su njihovi očevi možda je najveća razlika koju primećujemo kod Pinga i Leonea. Ping veruje da je njegov otac moralan i častan i ne dozvoljava drugima da mu narušavaju ugled i govore loše o njemu. Paradoksalno je što on sam „narušava”" očev ugled svojim ponašanjem i vezom s maćehom, kao i vezom $s$ devojkom koja je iz nižeg društvenog sloja. Ova Pingova samoobmana i idealizacija očeve figure ne dozvoljava mu da pronikne u bit svog konflikta sa sobom, za koji je odgovoran upravo njegov otac, mada vidimo da je na trenutke to osvestio dok je bio u vezi s Fanji. Motivaciju za njegovo ponašanje i slepo obožavanje oca možemo pronaći i u patrijarhalnom konfucijanskom konceptu sinovljeve poslušnosti, prema kojem deca treba da slušaju roditelje i da ne dovode u pitanje njihove odluke i ponašanje. Nasuprot Pingu, Leone stoji protiv svoga oca i svestan je njegovog nepoštenja i okrutnosti, on se stalno oseća kao da nosi teret Ignjatovih zlodela i svesno ga izaziva. Nažalost, svest 0 očevim manama ne donosi Leoneu razrešenje, te, kad mu otac umre, shvati da se borio protiv "fikcije oca", da njegova smrt nije rešila Leoneove unutrašnje nemire i nije donela katarzu (Gjurgjan 2003: 61). Glavno osećanje prema ocu kod Pinga je strahopoštovanje i potisnuta mržnja, a kod Leonea mržnja i potisnut strah od svoje "glembajevštine". Leone strahuje da je kao svoj otac, dok Ping želi to da bude. Tragičnost ova dva lika leži u tome

6 Pingov i Leoneov odnos s maćehama otvara veliku temu Edipovog kompleksa kod ovih junaka. Edipovim kompleksom kod Pinga na srpskom jeziku bavila se Pavlović (2015: 232-251), a na engleskom pogledati Wang (1994). Kada je reč o Leoneu Glembaju, detaljnu psihološku analizu njegovog odnosa sa Šarlotom dao je Klajn (1991). 
što u Leoneovoj prirodi postoji nešto glembajevsko od čega on neprestano beži, njegova „individualna samoobmana o nadmoći intelekta ruši se [...] pod težinom glembajevskih nagona koji uzimaju maha u njemu" (Brajović 1997: 31), dok je Ping drugačije naravi od svoga oca, iako bi želeo da je suprotno jer bi ga to oslobodilo pritiska i olakšalo mu namenjenu društvenu ulogu, prvo poslušnog sina, a kasnije i glave porodice.

*

Zahvaljujući Ibzenu, koji je bio značajan za stvaranje moderne drame ne samo na Starom kontinentu već i u Kini, mogli smo da povežemo stvaralaštvo Cao Jua i Miroslava Krleže, te da analiziramo na koje načine su koristili Ibzenovu dramsku tehniku, koja se, pre svega, odnosi na upotrebu simbola, retrospektivnu ekspoziciju i pažljivo psihološko građenje likova, kao i motive koji datiraju još iz antičke drame. Kada je reč o samim dramama, fokus rada je bio na poređenju odnosa i na razumevanju sukoba između očeva i sinova. Prednost smo dali Pingu i Leoneu, jer su nam drame pružile najviše uvida u njihove karaktere, ali smo se osvrnuli i na ostale sinove jer nam dodatno osvetljavaju mehanizme na kojima počiva patrijarhalni sistem u kojem očevi, kao autoritarne figure, dominiraju nad svojim sinovima. Sukob između očeva i sinova u Oluji i Gospodi Glembajevima leži u dubokom jazu između onoga što sinovi žele da budu i onoga što očevi očekuju od njih. Na kraju, nijedan sin u dramama ne uspeva da reši sukob s ocem i gotovo svi junaci imaju tragičan završetak.

\section{LITERATURA}

Brajović, T. 1997. Gospoda Glembajevi ili tragedija intelekta. U M. Krleža, Gospoda Glembajevi. Beograd: Zavod za udžbenike i nastavna sredstva, 7-32.

Cao Ju. 2003. Oluja, prevela sa kineskog M. Pavlović. Beograd: Filip Višnjić.

曹禺. 雷雨序. [Internet]. Dostupno na: https://zhidao.baidu.com/question/90284458. html [15.1.2020].

Gjurgjan, I. Lj. 2003. Fetišizam, vampirizam i pogled drugoga u drami Gospoda Glembajevi Miroslava Krleže. [Internet]. Dostupno na: https://hrcak.srce.hr/73884 [15.1.2020].

Ibzen, H. 1979. Aveti. Beograd: Jugoslovensko dramsko pozorište.

Klajn, H. 1991. Gospoda Glembajevi u svetlu dubinske psihologije. U Ž. Trebješanin (ur.) Frojd, psihoanaliza i literatura. Novi Sad: Matica srpska, 255-306.

Kralj, V. 1966. Uvod u dramaturgiju. Novi Sad: Sterijino pozorje.

Krleža, M. 1997. Gospoda Glembajevi. (ur. T. Brajović). Beograd: Zavod za udžbenike i nastavna sredstva.

Lau, J. S. M. 1970. Ts'ao Yu: The Reluctant Disciple of Chekhov and O'Neill: A Study in Literary Influence. HK: HKUP.

Lv Xiaoping. 2007. Ibsen and the Political Pragmatism of Modern Chinese Drama. In He Chengzhou (ed.) Ibsen and Modern China. North-West Passage, 181-189.

He, C. 2004. Henrik Ibsen and Modern Chinese Drama. Oslo: Unipub forlag. 
Maksimović, B. 2018. Slika porodice u Ibzenovoj drami Aveti i Cao Juevoj drami Oluja. Komunikacijaikultura. [Internet]. Dostupno na:https://www.komunikacijaikultura. org/index.php/kk/article/view/372 [15.1.2020], 141-158.

Pavlović, M. 2014. Moderna kineska drama i Henrik Ibzen. Beograd: Geopoetika.

Pavlović, M. 2003. Pogovor. U Cao Ju, Oluja. Beograd: Filip Višnjić, 189-205.

Vidan, I. 1968. Ciklus o Glembajevima u svom evropskom kontekstu. [Internet]. Dostupno na: http://dizbi.hazu.hr/object/9361 [15.1.2020].

Wang, N. 1994. A Chinese Version of the Oedipus Complex: Freudian Elements in Cao Yu's Leiyu. [Internet]. Dostupno na: http://ufdc.ufl.edu/UF00019686/00004/206 [15.1.2020].

\section{SUMMARY}

\section{COMPARATIVE ANALISYS OF THE RELATIONSHIP BETWEEN FATHERS AND SONS IN CAO YU'S THUNDERSTORM AND KRLEŽA'S MESSRS. GLEMBAY}

The aim of this paper is to give a comparative analysis of a son - father relationship in the plays Thunderstorm written by Cao Yu and Messrs. Glembay written by Miroslav Krleža. Both plays were significantly influenced by Scandinavian drama, especially Henrik Ibsen, and at first glance we can notice many similarities, both in the drama technique and the usage of similar symbols and motifs, which is shown in the first part of the paper. In the second half of the article, we analyse the relationship between fathers and sons and demonstrate how patriarchy shaped the conflict between these characters by creating authoritarian fathers and subordinate sons.

KEYWORDS: Chinese literature, Croatian literature, drama, comparative literature, Thunderstorm, Messrs. Glembay.

PODACI 0 ČLANKU:

Originalni naučni rad

Primljen: 11. novembar 2019. Ispravljen: 16. januar 2020. Prihvaćen: 17. januar 2020. 